\title{
IVÁN CHAPARRO*
}

* Profesor asociado Escuela de Diseño de Producto, Universidad de Bogotá Jorge Tadeo Lozano Maestro en Bellas Artes de la Konstfack, University College of Arts, Crafts and Design de Estocolmo, Suecia. Director Creativo del Laboratorio Transdisciplinario Resoundcity. ivanf.chaparrom@utadeo.edu.co

Sugerencia de citación: Chaparro, Iván. "Un oasis en medio de un basurero. Agencia política a través del diseño y las artes", La Tadeo DeArte 2(2016): 18-31, doi: http://dx.doi.org/10.21789/24223158.1164 

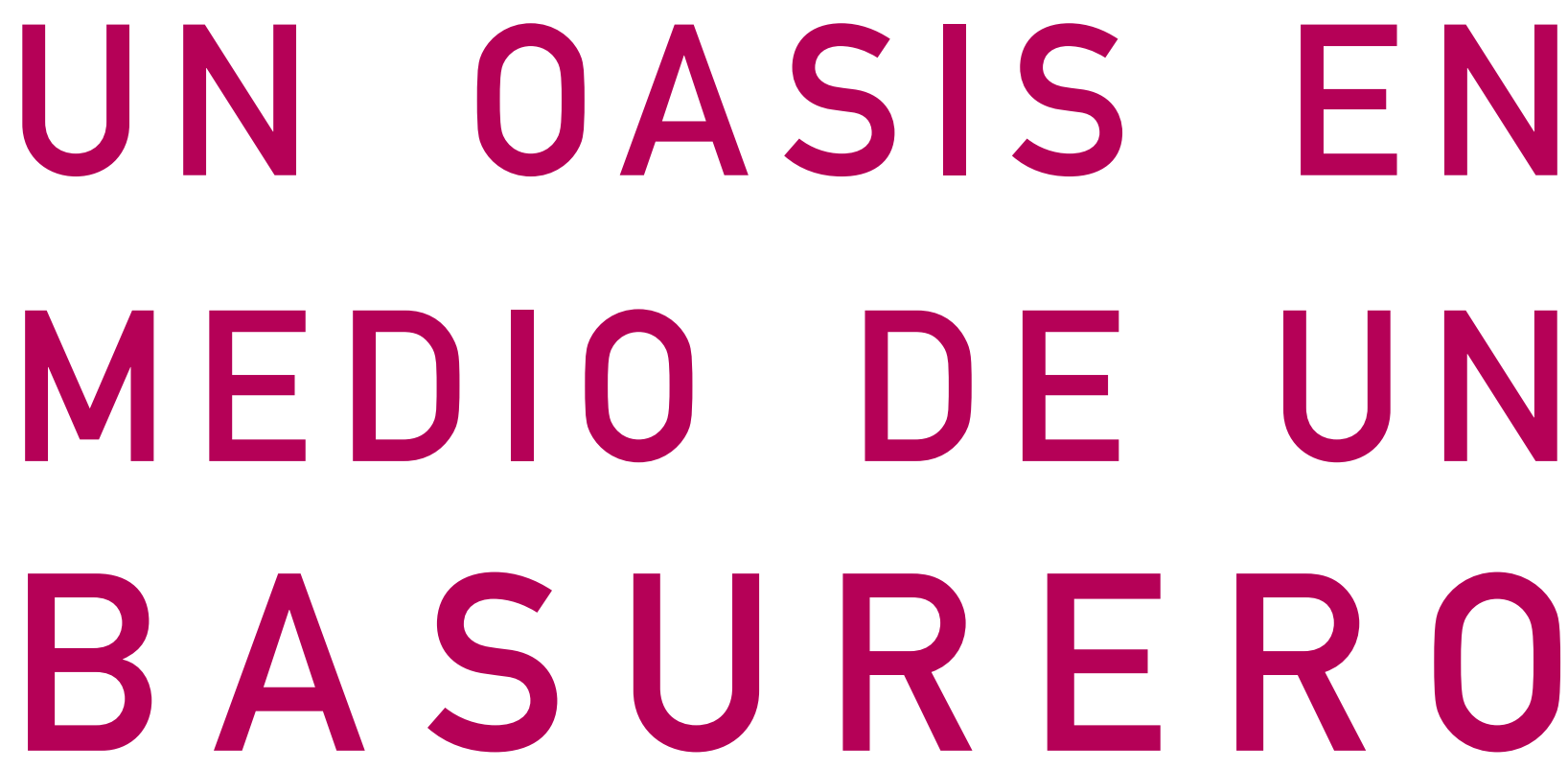

AgenCIA POLÍtica a través deL DISEÑO Y LAS ARtes

FOTOGRAFÍA CLOTILDE PENET 
Arte y DISEño Participativo

MÚSICA sollion

DESPLAZAMIENTO FORZADO 


\section{JOHAN HA VIVIDO 23 AÑOS EN MORAVIA;} «toda su vida», como él mismo recalca, ha habitado este barrio, que creció durante la década de los ochenta encima de un basurero abierto al aire libre, a dos kilómetros del centro de Medellín, la segunda ciudad más grande de Colombia. Johan recuerda cómo durante su infancia fue devuelto a su casa temprano desde su escuela debido a los enfrentamientos violentos entre varios grupos armados de la zona por disputas territoriales. Recuerda también que la calle central, hoy una concurrida avenida llena de comercio, era una pequeña trocha llena de grandes piedras y flanqueada por callejones estrechos.

Moravia está compuesto por cinco sectores, los cuales hacen que este barrio sea uno de los asentamientos más poblados del país (Arango), comparable en densidad con las favelas brasileñas y algunos barrios marginales de China (Baracaldo). Según el último censo (2005), el barrio tenía 42000 habitantes en un área de 42 hectáreas, es
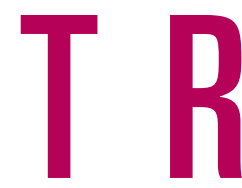

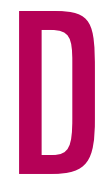

decir, una densidad de 1000 habitantes por hectárea y un promedio de 5 familias por casa. Toda la localidad ha sido regularizada e intervenida varias veces, lo cual le ha dado su aspecto actual de ciudadela laberíntica, llena de casas de fachadas altas y angostas, de entre dos y cuatro pisos.

En los años cincuenta prácticamente toda esta región era una zona frondosa, extensa y tranquila, atravesada por el río Medellín, popular por tratarse de un destino apetecido por los «paisas» para sus paseos dominicales. En 1956 se construyeron las primeras casas (Baracaldo), hecho que marcó el inicio de Moravia. La mayoría de estos predios pertenecían a familias adineradas, quienes decidieron abandonarlos cuando las primeras olas de migración forzada golpearon la ciudad, como resultado de la violencia en zonas rurales del país. Desde entonces, las familias acomodadas fueron mudándose al sur de la ciudad, al barrio El Poblado, definiendo así el extremo privilegiado de Medellín.

La ciudad comenzó a crecer hacia el sur y a finales de los setenta la Alcaldía decidió conver- tir Moravia en uno de los basureros principales de la ciudad. Desde 1977 el sector empezó a recibir los desechos de Medellín y sus 10 municipios cercanos en el Valle de Aburrá (Montoya et al.). La cantidad de desechos era tal que terminó convirtiéndose en una enorme colina de basura que para 1984 ya estaba totalmente saturada, lo cual obligó a la administración de la ciudad a reemplazarla por otra zona a las afueras de Medellín. El basurero abandonado fue paulatinamente ocupado por miles de víctimas de la violencia en Antioquia y zonas aledañas, las cuales buscaban refugio donde fuese, incluso en una montaña maloliente. Los nuevos habitantes de Moravia usaban basura compactada para construir ranchos temporales en las orillas del río Medellín; lo que para otros era una gigantesca pila de material en descomposición, era para ellos una oportunidad para vivir al menos en paz, aunque fuera sobreviviendo gracias a las sobras de sus vecinos.

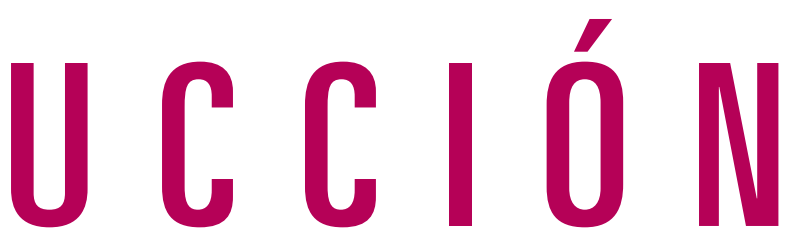

En menos de una década la colina llegó a tener 4265 familias (Baracaldo), quienes subsistían principalmente del reciclaje y otros trabajos informales. Durante los años ochenta, la presencia del M-19 y el aumento del tráfico de drogas tuvieron un efecto significativo en las zonas pobres de la ciudad y Moravia no fue la excepción, debido a su ubicación estratégica. A mediados de los ochentas, el narcotraficante Pablo Escobar empezó su campaña política para el Congreso colombiano, y como parte de su estrategia populista, transformó un campo de fútbol improvisado en el centro del barrio en una cancha gigante de grama sintética, con rejado e iluminación profesional. Además, Escobar ordenó la instalación del alcantarillado en el barrio y promovió un plan de viviendas como parte de su programa electoral, Medellín sin Tugurios.

A finales de esa misma década empezaron los intentos de la Alcaldía para reubicar a los habitantes de El Morro, una colina prominente dentro del cerro de desechos y una zona de alto riesgo. Solo fue posible hasta el 2005, gracias a subsidios de vivienda y al marco legal que 


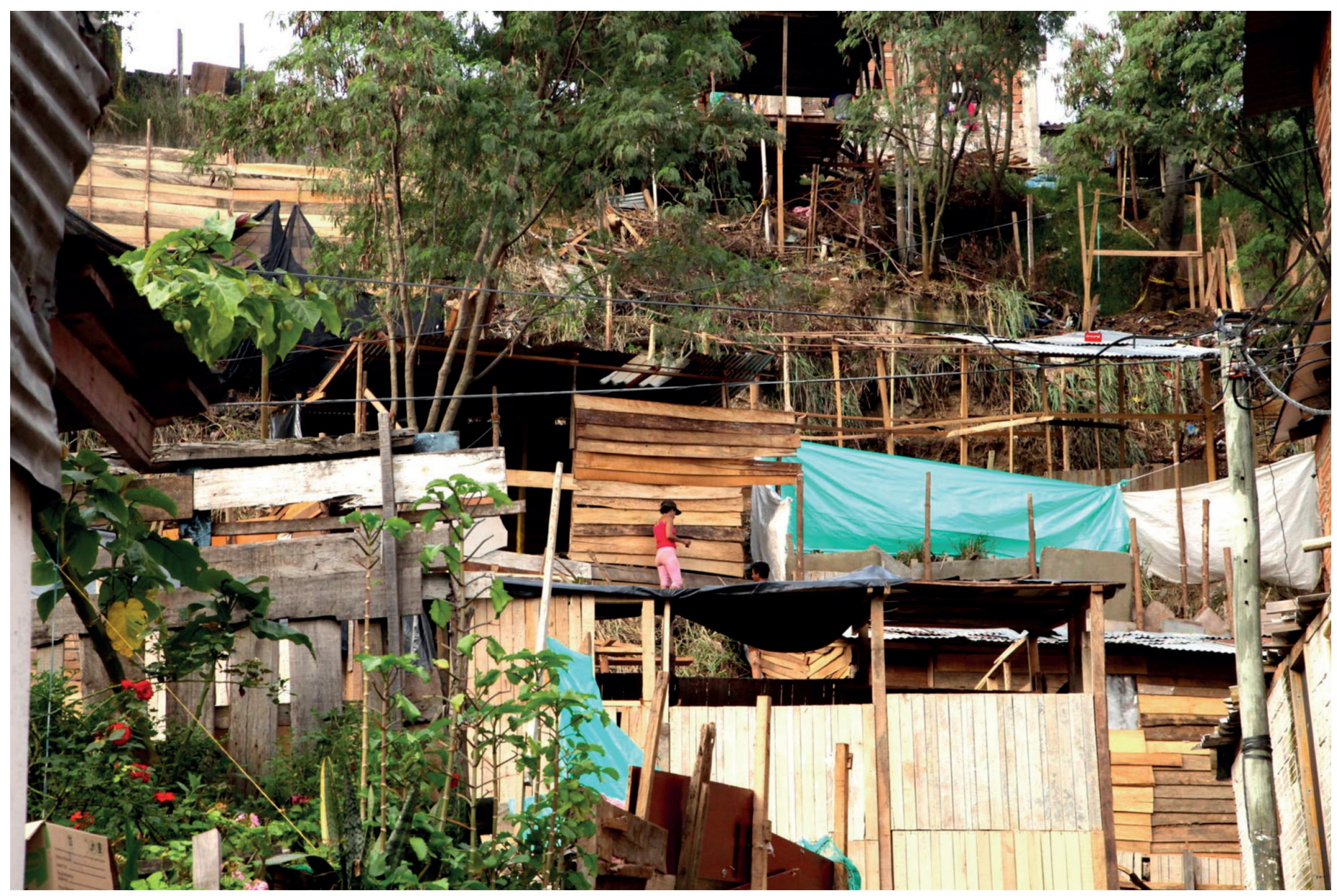

[ El Oasis, Moravia, Medellín, Colombia, 2015. ]

permitió el traslado de las familias residentes allí a edificios de apartamentos en Moravia misma y, principalmente, en otros barrios de la periferia de Medellín. En el 2014, 140 familias aún vivían en El Morro (Baracaldo). La iniciativa de reubicación Programa de Intervención Integral fue llevada a cabo entre el 2004 y el 2008, y abarcó Moravia y sus alrededores. Uno de sus resultados más destacables fue la creación del centro cultural y artístico del barrio, diseñado por Rogelio Salmona, uno de los arquitectos más prominentes del país. El centro fue inaugurado en el 2008, lo que cambió significativamente el panorama cultural de la zona.

Johan recuerda cómo la intervención cultural y arquitectónica cambió la imagen del barrio: «Todo se tranquilizó cuando era adolescente y así se ha quedado hasta ahora [...], como era tan joven no pensaba en eso, así que solo estaba feliz de poder caminar por la calle sin preocuparme». El ex-basurero se convirtió en ejemplo de renovación urbana y el Centro de Desarrollo Cultural de Moravia (CDCM) fue un elemento determinante para dicha transformación. Este lugar ofrece de forma gratuita programas educativos diversos relacionados con danza, música, artes visuales y cine, entre otros, además de servir como galería y escenario para proyectos creativos de la comunidad.

Johan tiene fuertes vínculos con el centro cultural; pasa mucho tiempo ahí practicando guitarra con muchos de sus compañeros, que también están involucrados en diferentes proyectos creativos. Isaac, uno de sus mejores amigos, fue reubicado durante su adolescencia, junto con su familia, en Robledo, un barrio situado en la parte nororiental de la ciudad. Sus lazos con Moravia son tan fuertes que afirma con seguridad que «vive en Moravia, pero duerme en Robledo». Durante los últimos años ha trabajado en el CDCM como profesor en un proyecto sobre cultura ambiental para las escuelas de Moravia y de barrios adyacentes, y el resto de su tiempo se la pasa «escribiendo líricas o pensado en música». 


\section{EL BULLA LAB: UNA INTERVENCIÓN URBANA EFÍMERA}

LUEGO DE DÉCADAS DE VIOLENCIA relacionada con el narcotráfico y el conflicto armado, Medellín ha experimentado en los últimos años una recuperación notoria, la cual se ha hecho evidente gracias a un compromiso especial con la educación y la innovación. Esta situación también se ha visto acompañada de una relativa estabilidad económica, evidente en la ola inmobiliaria en el sur de la ciudad. Una parte importante de esta transformación puede ser atribuida a la aparición de una red de sitios dedicados a la cultura como el CDCM, los museos en el barrio histórico y actores nuevos e independientes como la Fundación Casa 3 Patios (C3P), un centro de arte contemporáneo que investiga sobre pedagogía con impacto social, arte alternativo, urbanismo participativo, arquitectura y curaduría, entre otros. La entidad ofrece programas de residencia a creativos de diferentes disciplinas que quieran desarrollar proyectos relacionados con los intereses de la organización.

Como parte del programa de residencia que acoge a estos innovadores y con el apoyo del Ministerio de Cultura, fui seleccionado por la fundación C3P en julio del 2015 para llevar a cabo una investigación artística que consistió en explorar la ciudad a partir de las cartografías emocionales y las intervenciones urbanas efímeras. El concepto consistió en abordar un área urbana entendiéndola como una red de interacciones humanas e interpretándola desde una perspectiva psicogeográfica, es decir, como la manifestación de deseos, miedos, tensiones, conflictos, etc.

La parte práctica de la investigación comenzó en el CDCM con una convocatoria abierta para participar en un laboratorio de tres semanas denominado Lab de Acupuntura Urbana, el cual estaba dedicado a mapear y visualizar el barrio, para identificar las zonas de miedo y hostilidad en el espacio público. El laboratorio contó con un promedio de 20 participantes de entre 14 y 24 años, quienes en su gran mayoría habitaban Moravia, incluyendo a Isaac y a Johan como dos de sus miembros más activos.

La experimentación empezó con excursiones colectivas en el vecindario para recolectar información usando un kit de recolección de data, el cual constaba de varias piezas gráficas y herramientas simples: un manual infográfico con instrucciones, diferentes versiones del plano del barrio y un sistema de etiquetas (ver figuras 1, 2 y 3). La información a recolectar requería entender el barrio a partir de planos para mostrar aquellos lugares en los que cada quien se sentía incómodo o inseguro, por cualquier razón, usando una escala del 1 al 5 para calcular el puntaje y la intensidad de la sensación en ellos. El número 1 representaba una incomodidad somera y el 5, una incomodidad profunda. Las excursiones terminaban siempre con reuniones en las que todos los participantes discutían sus interpretaciones y subían su información a la base de datos que permitiría visualizar los datos obtenidos por todos los participantes. Para lograr esto, facilité unos tutoriales que permitían que cada miembro del Lab se relacionara con la herramienta web a partir de la cual las entradas de información alimentaban base de datos consolidada y accesible a través de cualquier navegador. 


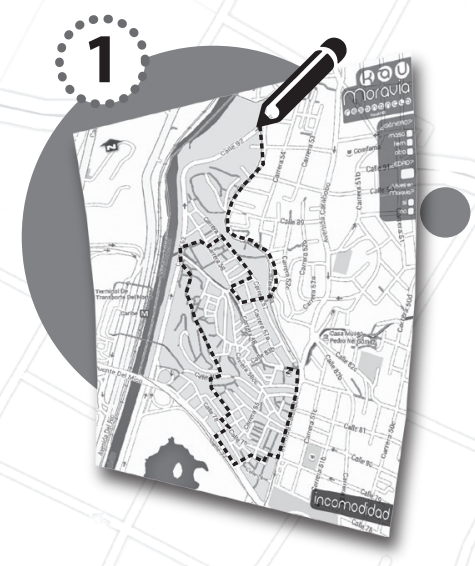

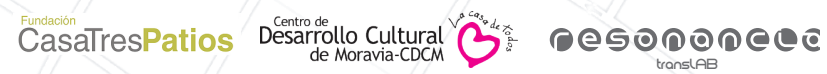
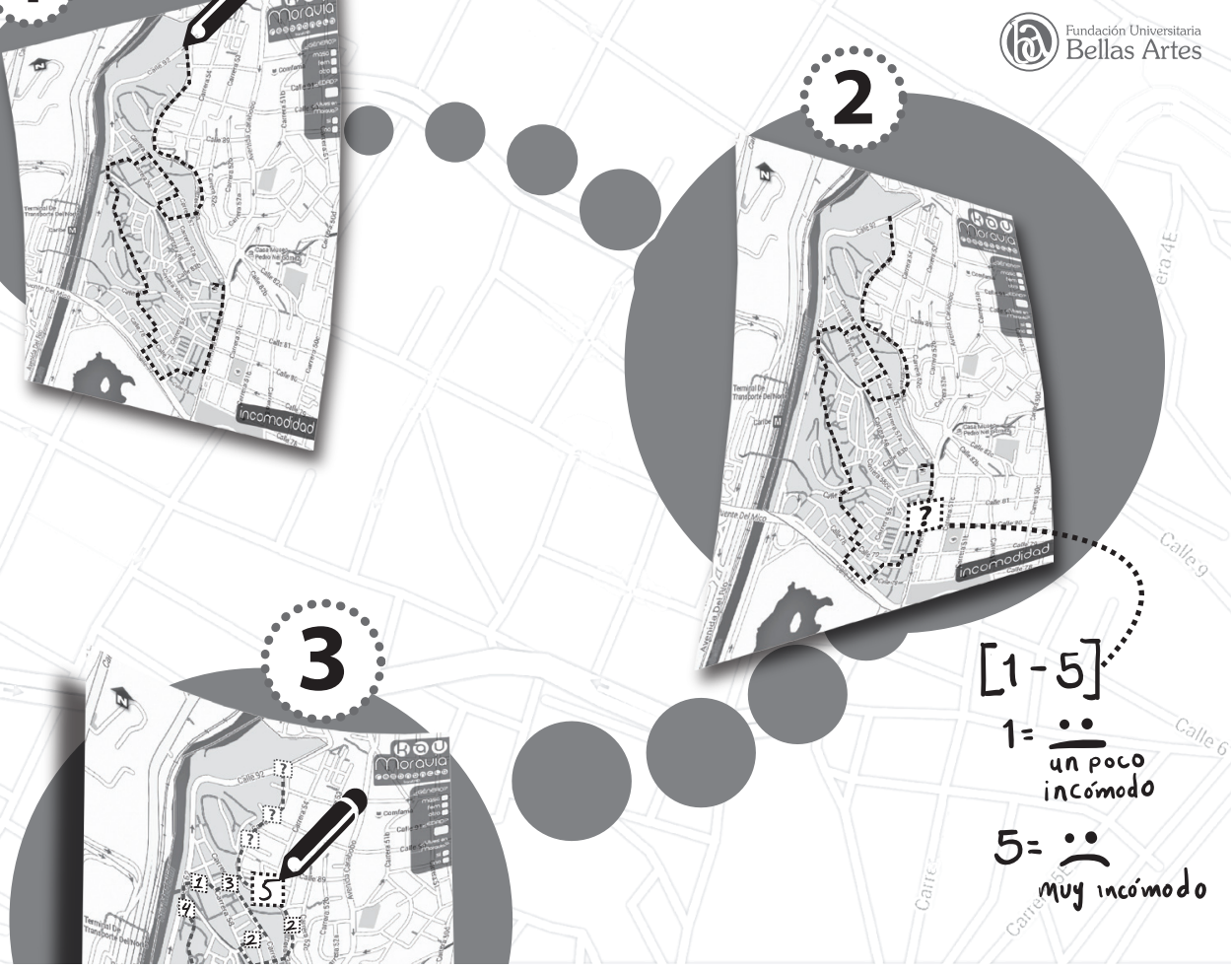

$5=\ddot{2}$

muy incómodo

[ Figura 1. Infografía con las instrucciones para la recolección de data en el barrio Moravia, Medellín, Colombia, 2015. ] Fuente: elaboración propia.

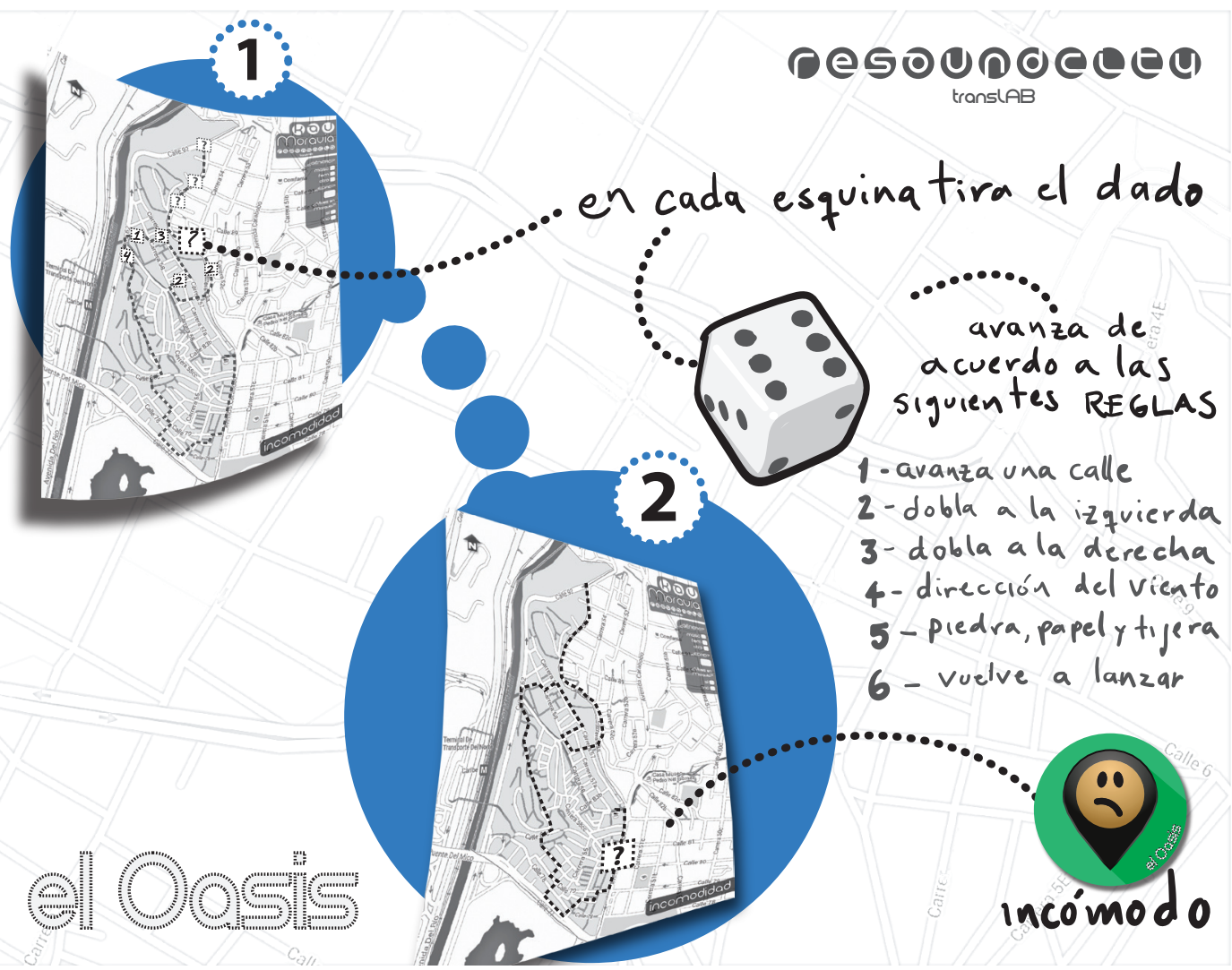

[ Figura 2. Infografía: instrucciones para perderse en el barrio recolectando data, Moravia, Medellín, Colombia, 2015. ] 


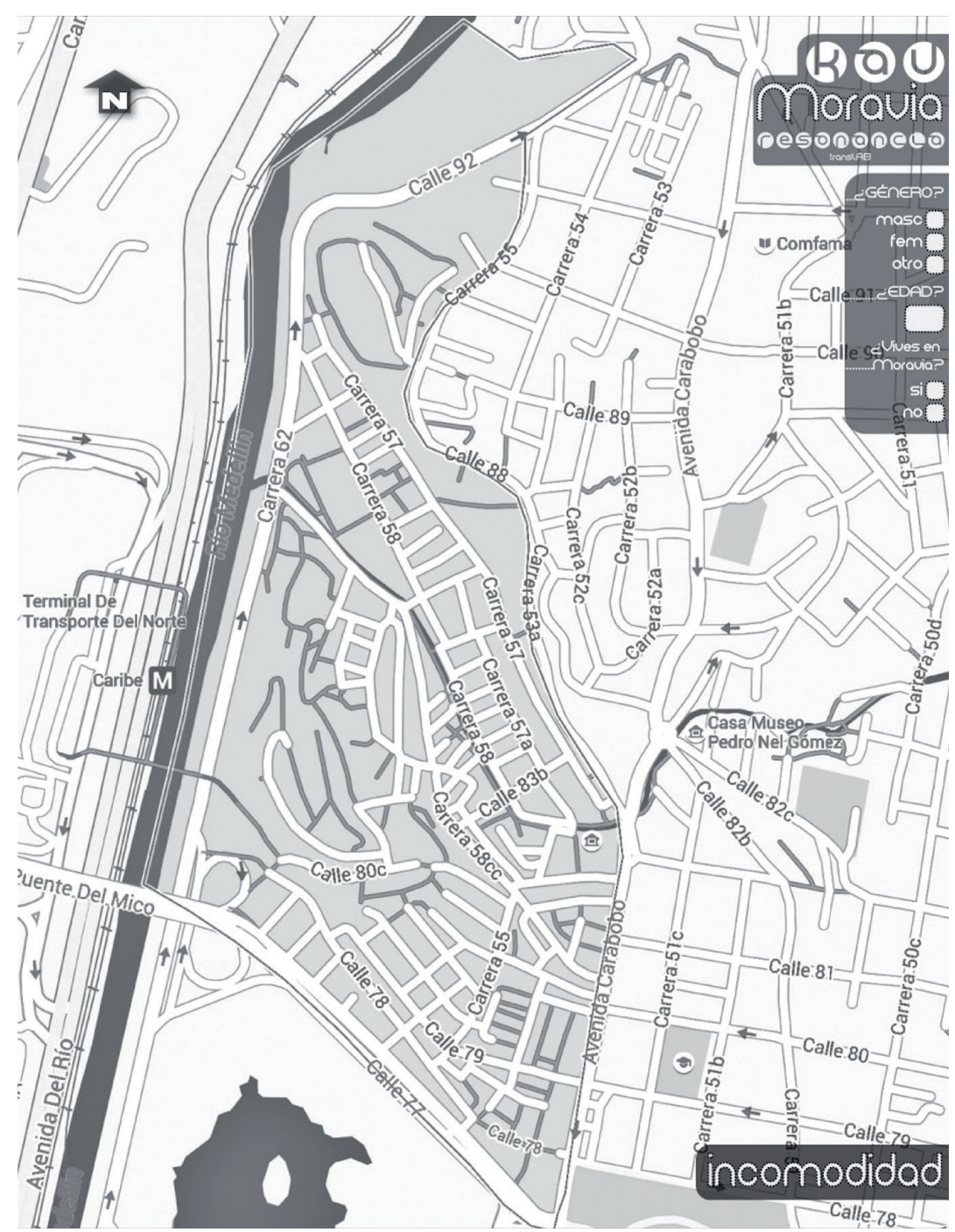

[ Figura 3. Mapa de Moravia: formato para mapear los lugares percibidos como incómodos o que producían miedo, Moravia, Medellín, Colombia, 2015. ]

Fuente: elaboración propia.

El sistema de recolección de data y de ingreso de información a la base de datos del proyecto fue diseñado en detalle, y el rol de todos en el laboratorio era el de actualizar sus entradas de información de acuerdo con sus recorridos por el barrio. Para ello, usamos una aplicación web basada en la API JavaScript de Google (https://developers.google.com/maps/documentation/javascript/), por medio de un navegador web, de modo que cada participante pudiera actualizar su información con base en cada excursión y siguiendo una secuencia simple de pasos. La aplicación que fue creada para este propósito estaba restringida a los límites de Moravia y permitía ubicar puntos en el mapa con su ponderación correspondiente del 1 al 5, usando la función place data. Las etiquetas de la API asignaban una coordenada GPS para cada entrada, con el objetivo de exportar la información consolidada de todos los usuarios a un archivo KML (Keyhole Markup Language), un sistema de notación para expresar información geográfica en mapas bidimensionales.

Un resultado espontáneo de este proceso de recolección y visualización de data fue la formulación de un laboratorio paralelo de experimentación con sonido y música, el cual fue bautizado por como el Bulla Lab. En Colombia la palabra 'bulla' hace alusión a un alboroto feliz o a una algarabía festiva. Siguiendo este simple concepto, el Bulla Lab se configuró como un espacio para experimentar con sonido en sesiones participativas en las que todos podían jugar con posibilidades electroacústicas para improvisar y componer música. 
A partir de las visualizaciones cartográficas obtenidas por medio de la base de datos, identificamos un lugar en el vecindario caracterizado por interpretaciones de incomodidad e incertidumbre, lo cual determinó que lo escogiéramos como el sitio en el cual podríamos realizar nuestros experimentos de acupuntura urbana. Se trataba de una intervención efímera participativa, planeada según las percepciones registradas del lugar, que buscaba involucrar a los habitantes de la zona en una creación colaborativa con el fin de cambiar la percepción negativa identificada en el punto visualizado. El lugar en cuestión fue un área en el barrio llamada El Oasis, una zona de 3 hectáreas junto al río Medellín, que en marzo de 2007 sufrió un incendio que destruyó 200 casas («Incendio destruyó 200 viviendas»). El área había permanecido vacía hasta que fue ocupada unas semanas antes de nuestra visita por un grupo de personas que buscaban dar una solución digna para sus condiciones de vivienda. Entre ellas, había un gran número de víctimas de desplazamiento forzado por diversos grupos armados, quienes habían tenido enfrentamientos con la policía poco después de asegurar sus asentamientos en la colina.

Moravia, el ejemplo más destacado que sirvió para mostrar la renovación urbana y la transformación social de Medellín a través de la cultura, ilustraba perfectamente la rueda de la historia y la tragedia social en el país. La ocupación de personas en situación de vulnerabilidad recordaba los orígenes mismos del barrio.

Después de unas cuantas visitas a El Oasis, empezamos a trabajar con sus residentes. Wilder, uno de los líderes de la comunidad, tuvo la iniciativa de ilustrar en hojas y pedazos de cartón letreros que narraban cómo él y su comunidad habían sido desplazados en varias ocasiones por diferentes actores armados en Colombia, y ahora, después de su interminable diáspora, iban a ser desplazados una vez más por el Estado colombiano, representado por la policía antidisturbios, la cual estuvo presente de manera frecuente durante nuestras intervenciones.
[ Figura 4. Cartografía emocional de Moravia que muestra en rojo a El Oasis. ] Fuente: elaboración propia.

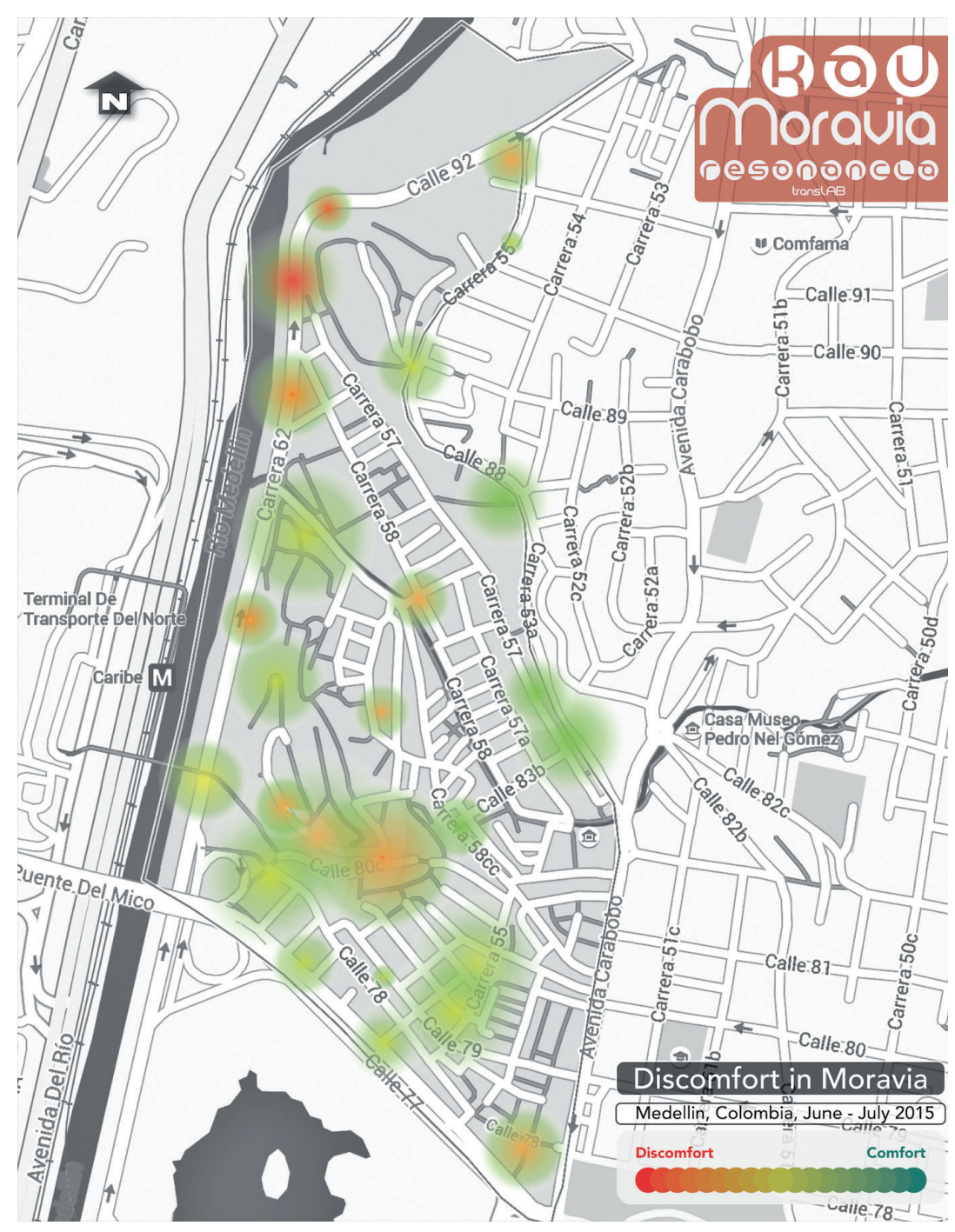




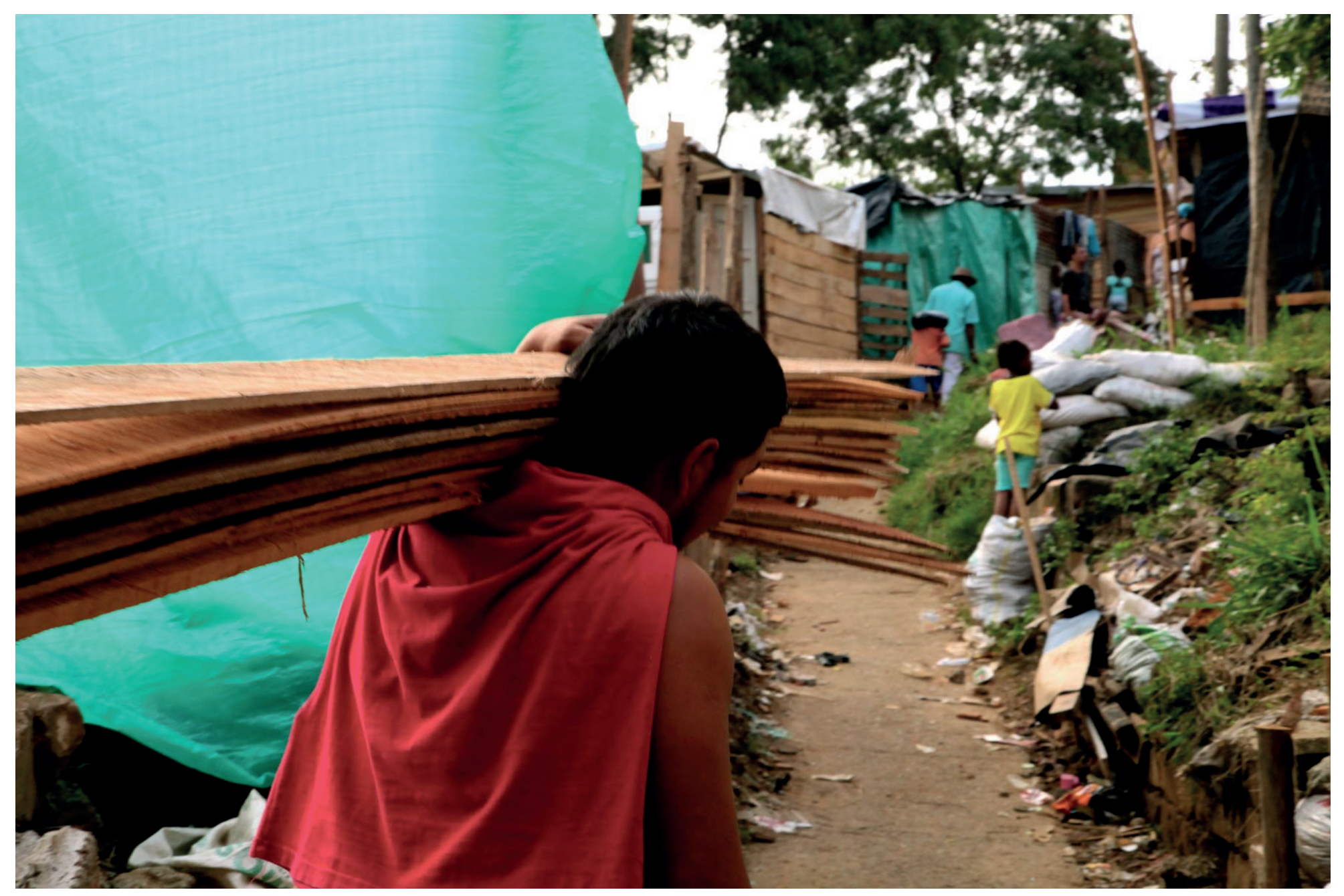

[ El Oasis, Moravia, Medellín, Colombia, 2015.] 


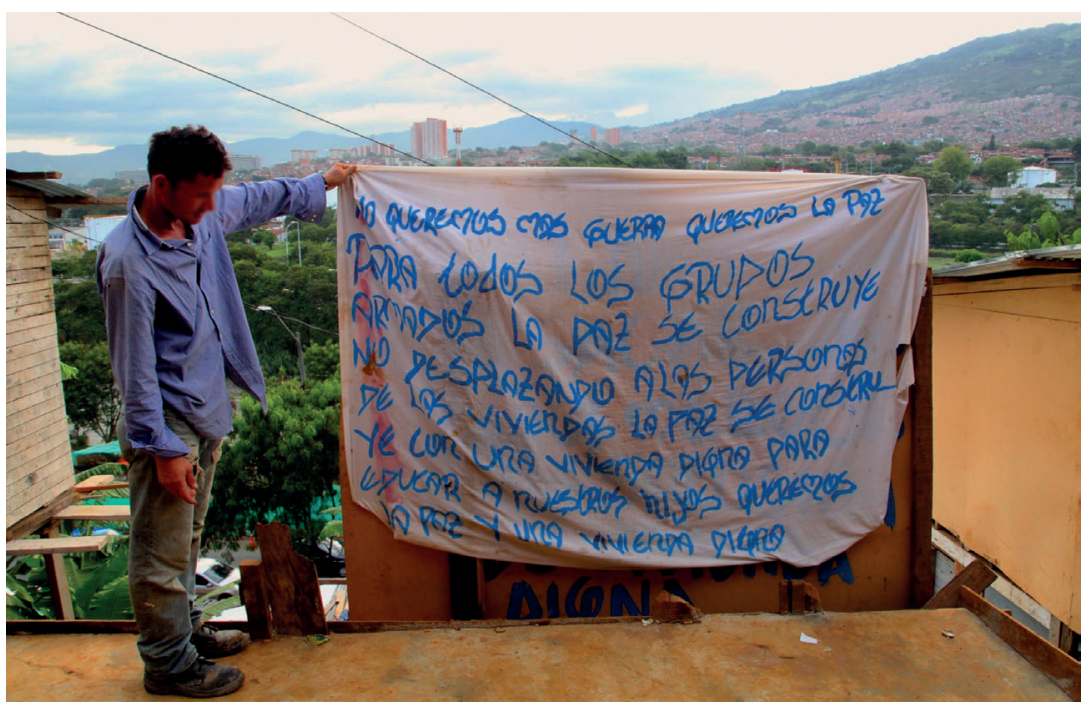

[ El Oasis, Moravia, Medellín, Colombia, 2015.]

Con los miembros del Bulla Lab organizamos talleres de sonido para niños entre 4 y 12 años de El Oasis, quienes esperaban ansiosamente a los miembros del laboratorio para su actividad diaria de las 4 de la tarde. La tarea consistía en la producción de instrumentos simples con materiales reciclados proporcionados por la misma comunidad, con los cuales interpretábamos después canciones folclóricas que los niños sabían de memoria. Simultáneamente, el Lab facilitó la logística para que los adultos continuaran con sus manifestaciones artísticas de dibujo y pintura para expresar sus experiencias de desplazamiento. Este proceso de acompañamiento fue titulado Bulla en Oasis.

Todos los días, después del taller con los niños de El Oasis, alrededor de las 6 de la tarde, el Bulla Lab regresaba al CDCM, donde montamos un estudio de grabación para ensayar las canciones que componíamos, basados en nuestro trabajo con la comunidad. La mezcla de música y las discusiones sobre nuestras experiencias en Moravia resultaron permeando muchas de las líricas de nuestras canciones.

De estas jornadas surgieron las Sesiones de Bulla, a cargo del Colectivo Pura Bulla, - que se configuró durante estas pocas semanas-compuesto por: Incognito Isaac', Johan Gutiérrez, Jorge Londoño, Clotilde Penet, Karen Correa, Alejandro Araque e Iván Chaparro. ${ }^{1}$

El proyecto concluyó después de cuatro semanas con una muestra fotográfica en El Oasis de la documentación del proyecto a través de las imágenes capturadas por la periodista Clotilde Penet y la colaboradora de C3P Karen Correa. La intención de esta muestra fue crear un pequeño museo urbano al aire libre. Unas semanas después, el miércoles 18 de noviembre a las 2:30 de la madrugada, la policía antidisturbios de Medellín irrumpió en lugar para desalojar de sus viviendas a varias de las 117 familias asentadas allí. Entre los afectados por la operación y la confrontación directa con los policías hubo niños, mujeres embarazadas y ancianos, quienes presentaron lesiones por la inhalación de gases lacrimógenos y los golpes recibidos. 38 viviendas fueron desalojadas ese día (Caracol Radio; Colombia Informa; Contagio Radio; El Palpitar).

Después de la operación, un comunicado de la Secretaría de Gobierno aseguraba que unas pocas personas en situación de vulnerabilidad entrarían a un proceso de valoración, mientras que las demás familias tendrían que encontrar por sus propios medios dónde reacomodarse.

En los desalojos masivos de aquel 18 de noviembre participaron más de 500 policías del Escuadrón Móvil Antidisturbios y fueron registrados por la prensa los abusos cometidos: cinco personas fueron heridas gravemente, un bebé quedó con parálisis cerebral debido a los gases inhalados y varias personas tenían evidencias de golpes con objetos contundentes.

Muchos de los habitantes de El Oasis escaparon en varias ocasiones de escenarios de violencia en el campo colombiano, para encontrar un pequeño lugar en la ciudad en donde vivir en paz a pesar de la pobreza. Nunca imaginaron que ese nuevo refugio se convertiría también en un escenario de guerra. 


\section{CONCLUSIONES}

ES UNA REALIDAD que luego de que estas familias son desplazadas dentro de la misma ciudad sufren un fuerte incremento en sus costos de vida, se ven obligados a cambiar de oficio y experimentan una ruptura del tejido social que habían construido, lo cual genera serios efectos psicológicos al volver a convertirse en desplazados, esta vez por causa de actores institucionales.

El principal objetivo del proyecto fue poner en práctica actividades creativas, que pudieran desencadenar acciones participativas y solidarias en la comunidad de Moravia. A largo plazo, la investigación tiene la intención de demostrar que la apropiación de herramientas artísticas y de diseño en el espacio público puede inspirar formas de agencia cívica colectiva y transformaciones positivas en escenarios desatendidos por el Estado. Las intervenciones efímeras, lejos de ser el objetivo principal de la investigación, representan una excusa para la activación de una dinámica social en un contexto específico.

Mi papel como diseñador y artista en este proyecto fue el de facilitar y servir de productor para un grupo de participantes; mi tarea principal consistió en involucrar mis conocimientos y experiencia para apoyar los procesos en curso de la comunidad, en particular, en lo relativo a la comunicación, toma de decisiones y visualización de problemas particulares, todo ello con el fin de desarrollar una intervención comunitaria.

Uno de los principales atributos del proyecto consistió en mantener motivados a los miembros del laboratorio mediante la adaptación frecuente de sus objetivos y alcances durante el proceso. En un principio planeé realizar un proyecto relacionado con visualización de datos urbanos y fabricación de prototipos, pero las circunstancias demandaron que ajustara varias veces mis intenciones y suposiciones, para hacer lo que era pertinente para los miembros del Lab y la comunidad. Finalmente, y sin darme cuenta, la música se convirtió en una parte central del proyecto, lo cual me exigió aprender varias herramientas diferentes para grabar sonido en vivo y producir de música en estaciones de trabajo de audio digital, además de aprender a hacer hip-hop en una semana, un género que nunca encontré particularmente interesante antes de esta experiencia. Esta flexibilidad de aprendizaje sobre la marcha garantizó que tuviera un equipo de trabajo animado, que apoyó las implementaciones adicionales que realizamos y que terminaron por adquirir significado en su propio entorno.

Otro cuestionamiento común en este tipo de proyectos se refiere a las fronteras entre disciplinas e identidades profesionales. Dentro de esta y otras iniciativas similares, la respuesta creativa y práctica para tal división del trabajo es el concepto de prácticas híbridas, es decir, integraciones de conocimiento y metodologías y prácticas que permitan aproximarse al contexto de manera crítica. De este modo, el proyecto encontró inspiración y referentes directos en la pedagogía solidaria, el activismo, la agencia cívica, el diseño participativo y el arte relacional, entre otros, con el fin de construir nexos entre creatividad y transformación social.

Las ochenta familias que aún permanecen en El Oasis, más las treinta y ocho que fueron desalojadas aquel 18 de noviembre comparten una condición similar: todas han sufrido directamente las consecuencias del conflicto colombiano. Sus situaciones de desplazamiento son el resultado de un problema estructural en el que se involucran muchos actores, dentro de cuyas raíces están la desigualdad social y la falta de oportunidades que afligen al país.

Estas familias y muchas otras en situaciones similares comparten otra condición: todos ellos tienen una lucha cotidiana semejante, cuyo verdadero valor radica en estas maneras aparentemente pequeñas de organizar su día a día, de modo que puedan sobrevivir estos tiempos turbulentos sin perder su dignidad. 
NOTAS

1 Es posible ver la galería del proceso haciendo clic en este enlace: https:// www.flickr.com/photos/resoundcity/sets/72157656315395399. Igualmente, se pueden escuchar las canciones del colectivo aquí: https://soundcloud.com/ resoundcity/sets/colectivo-pura-bulla.

\section{REFERENCIAS}

- Arango, G. "Moravia una historia de mejoramiento urbano”. En: Memorias, Seminario Internacional Procesos Urbanos Informales. Bogotá, Colombia: Instituto Distrital de Desarrollo Urbano, 2006.

- Baracaldo, D. Moravia: el barrio que floreció sobre una montaña de basura. <http://www.kienyke.com/historias/moravia-medellin-el-barrio-que-floreciosobre-una-montana-de-basura/>. Kienyke Magazine. 2014. Web. 15 jun 2016.

- Caracol Radio. Desalojo de 38 familias en El Oasis terminó con enfrentamientos. <http://noticias.caracoltv.com/antioquia/medellin/desalojo-de-38-familias-enel-oasis-termino-con-enfrentamientos>. 2016. Web. 16 jun 2016.

- Colombia Informa. El Puente Madre Laura provoca desalojos masivos en Medellín. <http://www.colombiainforma.info/el-puente-madre-laura-provocadesalojos-masivos-en-medellin/>. 2016. Web. 15 jun 2016.

- Contagio Radio. Esmad desaloja violentamente a 38 familias en Moravia, Medellín. <http://www.contagioradio.com/esmad-desaloja-violentamente-a38-familias-en-moravia-medellin-articulo-17380>. 2016. Web. 15 jun 2016.

- Diario El País. Incendio destruyó 200 viviendas. <http://historico.elpais.com.co/ historico/mar012007/NAL/burn.html>. 2016. Web. 15 jun 2016.

- El Palpitar. En video: Con explosiones y lesionados terminó desalojo de familias en El Oasis. <http://www.elpalpitar.com/seguridad/2015/11/en-video-conexplosiones-y-lesionados-termino-desalojo-de-familias-en-el-oasis/>. 2016. Web. 15 jun 2016.

- Montoya J., Cuesta, O., Flecha, O., Viadé, E., Gallegos, A., and Morató, J., 2011. Moravia as a model of degraded urban areas transformation: sustainable technologies for integral restoration of river basin. En: Memorias Cátedra UNESCO de Sostenibilidad, Universidad Politécnica de Cataluña. 